1782 he started an annual course on materia medica in his private laboratory near Notre Dame.

P.-J. Macquer, the doyen of French chemists, died in 1784, leaving vacant the chair of chemistry at the Jardin du Roi. The chief two candidates were Fourcroy and C.-L. Berthollet (1748-1822) and, although Berthollet had the influential support of the Duc d'Orléans, Fourcroy was preferred. This was a fortunate choice, for Fourcroy was able to develop his great talent as a teacher, while Berthollet, the better experimental chemist but a poor lecturer, succeeded to Macquer's other post as technical director of the Gobelins dye-works. From 1784 until his death twenty-five years later, Fourcroy lectured at the Jardin du Roi (later called the Jardin des Plantes), and twice the lecture theatre had to be enlarged to accommodate the crowds who were eager to hear him. His knowledge of chemistry was profound, and his lectures included accounts of the latest discoveries. He was a lucid and eloquent speaker, and sometimes drew applause from his audience during a lecture.

In the laboratory, Fourcroy was as active as in the lecture theatre, and he published many memoirs on all branches of chemistry. His study of the action of ammonia on salts led to the discovery of double salts such as magnesium ammonium sulphate; but most of his inorganic research was of little significance. His chief interest was in the examination of organic substances, and in much of this work he benefited from the collaboration of N.-L. Vauquelin (17631829), a first-class experimental worker. They analysed many of the liquid and solid parts of plants and animals by extraction with solvents, examined the properties of the products, and in some cases tried to relate their results to those of the older method of analysis by distillation. Later they measured the relative amounts of carbon, hydrogen, oxygen and nitrogen in a number of organic substances, and although little of their work was of lasting value, it was influential at a time when organic chemistry was in its infancy.

Fourcroy was always interested in the application of science to medicine. In his course of materia medica he examined the composition and mode of action of the common medicaments, and showed that many were useless or even harmful, and some of his later memoirs dealt with the chemical effects of medicaments on the fluids and tissues of the body. $\mathrm{He}$ encouraged others to take a scientific interest in medicine by founding and editing a journal, $L a$ Médecine Éclairée par les Sciences Physiques.

Even before his election to the Academy of Sciences in 1784, Fourcroy frequently met Lavoisier, and at the end of 1786 he accepted the anti-phlogistic theory and soon became its most vigorous exponent. This was probably his most important contribution to chemistry, for his books were very widely read. In the first edition of his text-book, "Leçons Élémentaires d'Histoire Naturelle et de Chimie", published in 1782, he had favoured Macquer's modification of the phlogiston theory; but in the four editions published between 1786 and 1793, all of which were translated into English, he gave his support to Lavoisier's theory. In 1792 he summarized the new theory and its applications in a small book entitled "Philosophie Chimique", which was reprinted or revised four times and was translated into at least ten languages, and his lectures, which were attended by many foreign students, also contributed largely to the rapid spread of the theory.
Fourcroy supported the French Revolution, and in $1793 \mathrm{he}$ was elected to the Convention. He intervened in few debates; but, while France was at war with most of Europe, he played a leading part in the application of science to such problems as the manufacture of gunpowder and cannons, in the organization of factories, and in the education of engineers and doctors.

In 1797 he was able to resume his scientific work, and found time to write his last and greatest book, "Système des Connaissances Chimiques", which appeared in eleven volumes in 1801; but his organizing ability could not be wasted, and Napoleon called him to the Council of State. He became director of public instruction, and was largely responsible for the foundation of the Université Impériale, which comprised the entire educational system of France from the elementary schools to the Institut. Fourcroy confidently expected to become the first 'grand master' of the Université, and ho received a severe blow when Louis de Fontanes was given the office. He continued his scientific work and lectures, but the disappointment affected his health; and he died on December 11, 1809, the day that Napoleon made him a Count of the Empire.

\section{BRITISH ASTRONOMERS AT THE TOTAL SOLAR ECLIPSE OF JUNE 20}

\author{
By Prof. R. O. REDMAN, F.R.S.
}

$T$ $\mathrm{HE}$ forthcoming total eclipse of the sun of June 20 is one of rather unusual interest in that the maximum duration of totality on the centre line will exceed $7 \mathrm{~min}$. and is not much below the maximum possible at any eclipse. It will be one of the longest eclipses of this century. The belt of totality starts in the.Indian Ocean at sunrise, passes over Ceylon, the Andaman Islands, Thailand, French Indo-China, and the Philippines, and ends at sunset in the Pacific Ocean north of Fiji. Unfortunately, the weather prospects are poor along most of the track ; the best chances of a clear sky are in eastern Ceylon, where totality will last for about five minutes. The central hills of the island will give some protection against the south-west monsoon, and mideclipse occurs at about 8 a.m. local time, which meteorologically is likely to be as favourable a time of day as any. Weather records from earlier years give a 60 per cent chance for clear sky ; but the usual sunshine and cloudiness data are designed primarily for other purposes and give a rather imperfect assessment of the sky for intending eclipse observers, whose work can be ruined by factors not appearing in the records, for example, light cirrus clouds or excessive scintillation. Reports from astronomers already in Ceylon this year suggest that the chances of a really satisfactory sky at totality are well below the 60 per cent quoted.

Astronomers from Britain, France, Germany, Holland, Japan, Switzerland and the United States are intending to observe the eclipse. So far as is known, with the exception of two small groups who are to use aircraft in Indo-China and Fiji respectively, all are going to Ceylon and will be stationed at a number of sites in and near Polunnaruwa. In this article we shall confine ourselves to an outline of the British plans. 
It is less than a year since the last total eclipse, in Sweden, where British observers were among the minority who had a sufficiently clear sky to complete most of their programmes of work successfully. This year's work from the ground will consist mainly of a repetition of some of the 1954 observations, with improvements in instruments and procedure suggested by the experience gained in Sweden. Last year, Dr. H. von Klüber (Cambridge) and Dr. A. H. Jarrett (St. Andrews) succeeded in the technically difficult feat of photographing the corona through a Fabry-Perot interferometer using the light of the green $5303 \mathrm{~A}$. line. Measurement of the fringes has given a distribution over the inner corona of the line width and hence of the kinetic temperature, and this year the experiment will be repeated, using a larger solar image and photographing in the light of the red $6374 \mathrm{~A}$. line, ఓs wall as in $5303 \mathrm{~A}$.

Prof. C. W. Allen and Dr. E. W. Foster (London University Observatory) will again be engaged in photomstry and spectroscopy of the corona with the general purpose of testing theoretical models of the electron $K$ corona and the dust $F$ corona. The special feature of the camera to be used for photometry is an occulting disk mounted on a tower at some distance from the lens. Its purpose is to equalize the intensity of the inner and outer corona, so that both may be satisfactorily photographed in one exposure. Their second instrument, a fast spectrograph, is also designed to record the outer and inner corona simultaneously on one photograph. An absolute photometric standardization will be provided and the polarization of the corona also will be measured.

Prof. E. Finlay-Freundlich (St. Andrews) had intended to go to Ceylon to co-operate with astronomers from the Potsdam Observatory in measuring the Einstein displacement in the star field surrounding the sun. Owing to ill-health, he has been prevented from travelling; but the Potsdam observers and equipment are in Ceylon, and will be assisted by Dr. von Klüber, who worked on this problem with Prof. Freundlich at the 1929 eclipse in Siam.

Finally, Dr. D. E. Blackwell (Cambridge), who in 1954 succeeded in photographing the outer corona from an aircraft flying at $30,000 \mathrm{fc}$. and thence in obtaining good photometric measurements out to a much greater distance from the sun than ever reached before, is this year to attempt to photograph the outer corona and zodiacal light after the eclipsed sun has set. The dust which produces the $F$ component of the corona is believed to be closely associated with that giving rise to the zodiacal light, and the problem is to bridge the existing large gap in photometric measures between the two. The ordinary zodiacal light cannot be observed with the eclipsed sun abovo the horizon, as the sky is then much brighter than often supposed, because of light scattered in from the sides of the moon's shadow as a kind of dawn. The device of working with the eclipsed sun below the horizon has been tried a few times by other observers, but so far without success. Dr. Blackwoll will work at about $10,000 \mathrm{ft}$. over the open Pacific Ocean, in a Sunderland flying boat based on Fiji. The aircraft will be provided by courtesy of the New Zealand Air Force, by arrangement with the Defence Services Research Facilities Committee of the Royal Society.

As at other recent eclipses, all British observers are working with the support of the Joint Permanent Eclipse Committee of the Royal Society and Royal Astronomical Society.

\section{OBITUARIES}

\section{Dr. Otto Rosenheim, F.R.S.}

THE announcement of the death on May 7 of Otto Rosenheim at the age of eighty-four will recall a friendly figure often seen at meetings of scientific societies in London, to many of which he was a notable contributor of highly original observations.

Rosenheim was born in Germany, where he took his Ph.D. degree at Würzburg, working under Tafel in Emil Fischer's laboratory. For part of the course he went to Bonn, and on completion of his degree to Geneva to work with Graebe. In 1895, through the mediation of Perkin, he went to Manchester for further study, and in 1901 joined Tunnicliffe in Halliburton's department at King's College, London, as research student in pharmacological chemistry; he was made lecturer in 1904, and on Tunnicliffe's departure became assistant professor of physiology. Later he became reader in biochemistry in the University of London--an appointment he relinquished in 1920.

After retiring for a few years from official duties, he went as a voluntary worker to the National Institute for Medical Research at Hampstead in 1925 , and so began a second period of research which lasted for another twenty years.

In the early period, during his association with Tunnicliffe, after some preliminary work on uric acid and the quadriurates, he investigated the toxicity of beer due to the presence of selenium, and also determined the proportion of formaldehyde in milk and food which would have no effect on healthy children. In after years, he often had resort to feeding experiments in intricate problems of sterol metabolism.

With Locke he took part in the classical investigation in which a new perfusion method was devised for the mammalian heart using dextrose in oxygenated Ringer solution; but his outstanding achievement at King's College was his arduous work on the constituents of the brain. In this he was ably assisted by Mary Christine Tebb, whom he later married. They laid the bogy of protagon, around which unseemly controversy had raged. Thudichum, of whom Rosenheim was an ardent admirer, had shown in 1874 that protagon was a mixture; but Liebreich, Gamgee, Blankenhorn and Cramer believed it to be a molecular entity. Rosenheim and Miss Tebb demonstrated how dried brain treated mildly with solvents could be soparated into free cholesterol, two phosphorus-free galactosides (phrenosin and kerasin) and a phosphorus-containing residue of sphingomyelin. The structures advanced by Rosenheim for phrenosin and kerasin are close to those now accepted.

In 1909 Rosenheim examined extracts of placenta, showing that if there was no putrefaction there was no pressor effect. Dixon and Tayler had elaimed the contrary. Incidentally, Rosenheim identified tyramine as a product of putrefaction.

During his period of temporary retirement, Rosenheim, who was an enthusiastic rock-gardener, interested himself in some problems posed by the pigments of edelweiss and young vine leaves.

On coming to the National Institute for Medical Research in 1925, Rosenheim brought with him the problem of spermine phosphate, the conditions for the isolation of which he and his wife had already worked out. With Dudley and later with Starling's 